\title{
Task complexity effects on the complexity and accuracy of writing via text chat
}

\author{
Rebecca Adams ${ }^{\mathrm{a}}$, Nik Aloesnita Nik Mohd Alwi ${ }^{\mathrm{b}}$, Jonathan Newton ${ }^{\mathrm{c}, *}$ \\ a Northcentral University, 10000 E. University Drive, Prescott Valley, AZ 86314, USA \\ b Centre of Modern Languages E' Human Sciences, Universiti Malaysia Pahang, Lebuhraya Tun Razak, Kuantan, Pahang 26300, Malaysia \\ ' School of Linguistics and Applied Language Studies, Victoria University of Wellington, P.O. Box 600, Wellington 6140, New Zealand
}

\section{A R T I C L E I N F O}

Keywords:

Task complexity

Linguistic accuracy

Linguistic complexity

Text chat

Writing-to-learn

\begin{abstract}
A B S T R A C T
Despite limitations with text chat as a mode of writing (e.g., a simplified register, short turns), researchers have argued that it offers unique advantages as a site for language practice. However, realizing these advantages in second language (L2) writing-to-learn environments may depend on whether tasks are implemented in a way that facilitates learners' attention to language form in their writing. It follows that the design and selection of appropriate tasks to use in Computer-Mediated Communication (CMC) are key issues. Inspired by the Cognition Hypothesis (Robinson, 2005), the current study examined the role of two instructional interventions related to task implementation-the amount of task structure and inclusion of language support-in promoting accurate and complex writing via text chat by $\mathrm{L} 2$ learners in a classroom setting. Data were collected from 96 students performing an engineering simulation task via text chat. The learners were placed in one of four counterbalanced experimental groups. Analysis of the chat exchanges provided evidence that task complexity influenced the accuracy of student writing in line with the Cognition Hypothesis. However, the influence of task complexity on the linguistic complexity of their writing failed to match predictions of the Cognition Hypothesis.
\end{abstract}

(c) 2015 Elsevier Inc. All rights reserved.

\section{Introduction}

Communication in virtual environments has opened up opportunities for second language communication and learning (see Kern, Ware, \& Warschauer, 2008, for a comprehensive analysis of this topic). As computer technology use has become ubiquitous in professional and personal communication, the ability to communicate effectively via this medium has become a requisite aspect of language competence (Thomas \& Reinders, 2010). For second language learners, the changes in communication brought by technology have both introduced a new learning need (to be proficient communicators in Computer-Mediated Communication, or CMC) and increased opportunities for learning via CMC. CMC technology increases the space available for communication and collaboration, because it can take place with the person seated at the computer next to you, or with someone on the other side of the world, whether between native speakers and learners or among learner peers (cf. Blake, 2007; Chapelle, 2004). Research overall has indicated that communicating in a second language via CMC has unique benefits for language learning (see Sauro, 2011 for a full overview). From a teaching perspective it also offers unique

\footnotetext{
* Corresponding author.

E-mail addresses: radams@ncu.edu (R. Adams), aloesnita@ump.edu.my (N.A. Nik Mohd Alwi), jonathan.newton@vuw.ac.nz (J. Newton).
} 
advantages: CMC-based peer interaction can easily be implemented in large classes; it can encourage participation among more reticent learners (Chen \& Wang, 2009); and it allows the teacher the means to monitor multiple interactions.

CMC occurs in two modes: asynchronous (such as e-mail, online discussion forums, and podcasts) and synchronous (such as text or video chat). Communication unfolds in very different ways in these two modes. Asynchronous CMC is more analogous to pen and paper writing, in that it allows time to compose and edit thoughts before making them public (Kitade, 2008). In contrast, synchronous computer mediated communication (SCMC), although a written medium, unfolds in real time and shares many of the characteristics of spoken dialogue (Blake, 2009). In both forms, CMC represents a new extension of writing. Just as technology is changing the way people read (e.g., anchored by screens of flowing text rather than pages) it is also changing the way people write. CMC has introduced new technologies for writing as well as new models of distributing our writing. This is changing our understanding of the role of audience response and interactivity in writing. Understanding text-based CMC and its role in writing-to-learn-language (WLL) is increasingly important for understanding the connection between writing and learning, whether within or beyond the second language (L2) classroom.

To address these needs, the current study examines how writing via CMC under different task conditions promotes language learning among students preparing for professional second language communication. Essentially, this research clarifies whether learners' written language production and learning opportunities are different depending on how second language computer-based writing tasks are implemented. We focus on two task conditions-the amount of structure given to learners directing them how to complete the task, and opportunity for guided pre-task language practice-to determine whether these influence the complexity and accuracy of written communication in a CMC environment. These variables were selected for their pedagogical value: teachers can easily manipulate CMC tasks in these ways in real classrooms. For this special issue, this is the only study to examine CMC writing. As such, it reflects the broadened scope of writing in the Internet age. It is also the only study to examine task complexity effects on both the complexity and accuracy of second language writing, extending the discussion of complexity in second language writing-to-learn.

\section{What is text chat?}

While synchronous CMC (SCMC) can occur in video and audio formats as well, bandwidth restrictions, platform stability, and convenience make text-based SCMC (text chat) a common, reliable, and affordable means of SCMC in educational settings (Johnson, 2006; Traphagan et al., 2010). Text chat combines characteristics of speaking and writing (Smith, 2003). Like spoken language, it is a rapid, spontaneous exchange of information in real time. Like writing, it results in a relatively permanent, visual record of the discourse. However, it is not simply a hybrid of speaking and writing. Text chat also includes unique characteristics. Even though text chat discourse unfolds in real time, the production and transmission of messages are disassociated, with each turn in a text chat discourse fully formed before it is visible to other interlocutors. This allows for discourse effects atypical in other modes of communication. First, in a group setting, multiple interlocutors can produce messages at the same time, which can separate adjacency pairs as the discourse unfolds (Smith, 2009). Second, text chat produces a written record which can be reviewed as the communication evolves (Chun \& Payne, 2004). Third, text chat has a simplified register and syntax, a unique set of abbreviations, and uses symbols such as emoticons to express the author's attitudinal stance (Smith, 2003).

\section{Writing to learn through text chat}

A writing-to-learn-language (WLL) perspective on writing instruction emphasizes the role of writing as a medium for language development in contrast to the focus on writing skill development seen in the more traditional learning-to-write (LW) approach (Manchón, 2012a). The WLL perspective has proved a useful counter to the claim that much of the L2 writing research lacks relevance to learning in foreign language contexts (Manchón, 2009). As Leki (2009) remarks, "contrary to dogma in SL writing, with its now traditional de-emphasis of language learning, using writing to develop language proficiency may be a central aim of L2 writing in FL settings" (p. xv).

WLL draws largely on theorizing in SLA for its rationale, and particularly on research into the role of output in language development (Swain, 2000). Williams (2012) highlighted the role that output, and written output in particular, has been shown to play in the three main acquisition processes proposed by Housen and Pierrard (2005) of knowledge internalization, restructuring and consolidation. Two key features of writing distinguish it from oral production, its permanence and the slower pace at which it is produced, and it is these that make it particularly valuable for WLL by allowing for "more learner control over attentional resources as well as more need and opportunity to attend to language both during and after production" (Williams, 2012, p. 322). However, as Williams points out, the facilitative role of writing in language development shown in many studies should be more accurately seen as the result of writing instruction including "interaction and negotiation among writers during text reconstruction or pre-writing activities" (p. 323, see also Wigglesworth \& Storch, 2012). As we noted earlier, this interactive element is a fundamental feature of CMC and so provides a strong theoretical orientation to CMC research.

Chapelle (1997) pointed out that CMC research based on the Interaction Hypothesis (cf. Long, 1996) would allow for theory-based comparisons of the effectiveness of CMC in promoting language learning. The large body of research this claim has inspired has sought to determine the extent to which text-based CMC interaction promotes learning to the same degree as oral interaction as well as the variables that bear on this relationship. In a synthesis of SLA-based CMC research, Sauro 
(2011) reported widespread research evidence of the benefits of interacting in CMC, including instances of heightened noticing, form-focused episodes, and self-repair that arise during or as a result of interaction via CMC.

While much of the research has focused on interactions between native speakers and language learners, as in two-way virtual pen pal programs, several studies have examined interaction among language learning peers. Research on peer L2 interactions in text chat has consistently shown evidence of learning benefits such as, for example, incidental vocabulary acquisition (Smith, 2004). Studies focused on interactional modifications (e.g., Cheon, 2003; Lai \& Zhao, 2006; Smith, 2008) have shown that learners apply a range of strategies to resolve miscommunication and are able to use features like "cut and paste" from the chat transcript to pinpoint negotiation triggers (Lai \& Zhao, 2006). In a study investigating CMC writing by electrical engineering undergraduates with intermediate English proficiency, Nik, Adams, and Newton (2012) found that the students were more likely to engage in negotiation of grammatical than lexical focus on form during text chat, a pattern which runs counter to most oral interaction findings, possibly because of access to the evolving chat transcript, which may have prompted learners to attend more to form. These findings highlight the writing-to-learn affordances unique to text chat.

Not all studies in this area have reported favorable results for CMC. Loewen and Reissner (2009), for example, in a study investigating the incidence of focus on form episodes in face to face and text chat interaction by learners in tertiary ESL classes in New Zealand found greater occurrence of these episodes in face to face interaction. They also found that when teachers were moderating text chat interaction they tended to react negatively to conventions of text chat language use. To help teachers effectively leverage L2 writing through text chat in the classroom, research needs to address not just how peer learners engage in CMC interactions, but how the design and implementation of learning tasks can be managed to maximize the quality of CMC-based WLL opportunities.

It should also be noted that while focusing CMC research on the interactionist approach has highlighted the speech-like interactivity of CMC, learning in text-based CMC is not only learning through interaction, but also learning through producing written language. In the light of this research, text chat has been suggested as an effective medium for L2 practice and learning through writing (Ortega, 2009) and has been employed for writing-to-learn activities in various ways, such as developing intercultural understanding (Jin \& Erben, 2007), conducting collaborative tasks (Yilmaz, 2011), and promoting autonomous learning (Collentine, 2011).

Research has also shown how the written form of text chat affords learners' heightened opportunities to attend to language (Fiori, 2005; Sauro, 2009; Sotillo, 2005) since the written interaction makes language more salient (Lee, 2008). As Meskill (2005) points out, “computer screens can serve to anchor attention to forms” (p. 48). As such, communication via text chat may be a particularly good site for noticing, which can be prompted by either an interlocutor's feedback turn or by learners reviewing their own contributions to the chat transcript (Sauro, 2009). Lai and Zhao (2006), for example, found that intermediate proficiency ESL learners engaged in dyadic CMC and face-to-face interaction in low-high intermediate pairings were more likely to notice both their own errors and their partner's attempt to start negotiation sequences in text chat. This issue is a central focus of the current study.

From a writing perspective, enhanced attention to language form in text chat is likely to open up opportunities for leaners to write with more accurate and complex language. However, the discourse of text chat is not normally characterized by high accuracy and complexity. In general, text chat takes place with a simplified register, short turns, and chat conventions. Kern (1995) questioned whether learners would devote resources to monitoring their production in CMC when accuracy is not generally expected in the context. This prediction was borne out by Kung's (2004) research which examined the features of interaction produced during $40 \mathrm{~min}$ of online text chat discussions among 47 intermediate to low-advanced level of EFL learners in Taiwan. The leaners accounted for the large numbers of spelling, grammar, and lexis errors in their production by claiming that the need to continually produce language to remain "visible" in the chat led them to sacrifice accuracy for speed. Lee (2002) found that simply instructing learners to produce grammatical language was not enough to promote more accurate language. Despite these qualifications, overall, researchers have argued that text chat offers unique advantages as a site for language practice (for a full discussion, see Philp, Adams, \& Iwashita, 2014), a claim that is explored in this study in order to contribute to the WLL strand of L2 writing research (Manchón, 2012b).

\section{Task implementation in text chat}

While there are both advantages and drawbacks to text chat as a site for language practice, it is important to remember that it is not only the technology but also how it is used that influences how learners engage in communication. Thus, the design and selection of appropriate tasks to use in CMC is crucial for promoting learning (Peterson, 2010).

Prior research has shown that online tasks can be designed to elicit language output in ways that promote L2 development (Stockwell, 2010). For example, Yilmaz (2011) examined learning opportunities that emerged as learners engaged in dictogloss and information-gap tasks in CMC. The learners in his study focused more on linguistic form during the dictogloss task than the information-gap task. They were also more likely to arrive at a target-like solution when discussing language use in the dictogloss. His findings suggest that it is not only the online context but also the task learners are asked to do that influences whether and how they attend to language form.

The Cognition Hypothesis (Robinson, 2001, 2005) offers a framework to determine how to design tasks to focus learner attention on the accuracy, complexity, and fluency of their production. In this framework, Robinson argues that manipulating aspects of task design and implementation increases or decreases the cognitive complexity of communication 
required to meet task outcomes, thus pushing language development in particular and predictable ways (Robinson, 2001, 2005; Robinson \& Gilabert, 2007). Robinson (2001) reasons that understanding the comparative complexity of tasks is necessary if tasks are to be used as a unit of curriculum design (see Long \& Crookes, 1992).

The Triadic Componential Framework for task design (Robinson, 2007) considers three sets of factors which influence task performance: those related to task complexity, those related to the conditions under which the task is performed, and those related to learner perceptions of task difficulty. Task complexity (the focus here) deals with the intrinsic, cognitive complexity of task features and is further divided into two categories: resource-directing and resource-dispersing factors. In this study, we focus only on the second, resource-dispersing factors. Robinson predicts that increasing task complexity along resource-dispersing factors (e.g., performing a task with no prior planning, as opposed to performing a task with prior planning) increases demands on learner cognitive resources but does not direct them to aspects of form. For dialogic tasks, increasing task complexity along resource-dispersing dimensions is predicted to decrease the complexity, accuracy, and fluency of language production.

The Cognition Hypothesis has inspired a large body of research, most of which has focused on a few resource-directing variables (e.g., the number of elements in a task, the level of reasoning demands) in monologic (Gilabert, 2007; Kuiken \& Vedder, 2007; Tavakoli \& Foster, 2008) or interactive tasks (Nuevo, 2006; Nuevo, Adams, \& Ross-Feldman, 2011; Révész, 2009; Robinson, 2001). Several studies have also examined the effects of one resource-dispersing variable, pre-planning prior to task production in face-to-face settings (Ellis \& Yuan, 2004; Foster \& Skehan, 1996; Ong \& Zhang, 2010; Skehan \& Foster, 1997; Yuan \& Ellis, 2003). Only a handful of studies have examined task complexity in CMC tasks.

There is limited evidence that task implementation can push learners to attend to linguistic accuracy in text chat tasks. Fiori (2005) compared L2 production of learners who did or did not perform a consciousness-raising activity prior to engaging in a meaning-focused text chat. She found that learners who had done a consciousness-raising activity showed increased attention to accuracy in their text chat. Fiori noted that the effect of consciousness-raising activities was likely enhanced by text chat, because it allowed learners to review the messages as often as they wanted, helping them focus on form.

Adams and Nik (2014) examined the role of prior knowledge in text CMC peer communication. Similar to Fiori's work, their results suggest that prior knowledge of the task content leads to greater accuracy in L2 production in text chat. These studies evidence the possibility of learners focusing on accuracy in text chat communication if the task is framed through instruction that promotes this. Although text chat may be most commonly used for quick communication without focus on linguistic accuracy, this need not always be the case in instructional settings.

In addition to monitoring for accuracy, language production, and particularly written production, offers learners opportunities to stretch their linguistic resources by attempting to produce more structurally and lexically complex language. Focusing on using complex language can promote the emergence of new linguistic forms in language production (Skehan, 1998). As with linguistic accuracy, researchers have noted that the conventions of text chat, particularly the simplified register and frequent use of ellipsis and abbreviations may leave text chat a poor site for promoting complex production (Lund, 2006). As discussed earlier, Kung (2004) reported that learners most commonly produced sub-clausal units in his study. In interviews, the learners attributed their abbreviated turns to the necessity of adapting their typing speed to meet the demands of text chat, which pushed them to use simplifications.

However, other studies show evidence that learners can produce complex language in text chat. In Warschauer's (1995) study, for example, learners produced language that was both lexically more varied and syntactically more complex in online text chat than in face-to-face interactions. Sauro and Smith (2010) suggest that the disassociation between production and transmission in text chat, mentioned above, may promote greater complexity. When learners in their study used the opportunity to monitor and refine their production prior to transmission, they also produced more complex language. Similarly, Fiori (2005) found that learners who engaged in pre-task consciousness raising activities produced significantly more syntactically complex language than learners in a comparison group. In contrast, Adams and Nik (2014) found that prior knowledge of task content led to less complex language, possibly because learners with prior content knowledge were more likely to use their own language in their writing, while learners without prior knowledge were more likely to mine task materials.

While some researchers have tended to dismiss the possibility of complex and accurate language production in text chat because of conventions of style for casual use of text chat, using text chat in an instructional context is quite different from casual communication, and the research reviewed here suggests a complex picture of the uses and potential benefits of text chat. The spontaneous nature of chat can lead to a higher tolerance for inaccuracy and simplicity in production when used in naturalistic or causal settings. But equally, unique aspects of text chat as synchronous written communication including longer production time, the emerging chat transcript, and the disassociation of production and transmission of messages may lead to greater attention to form, resulting in greater accuracy and complexity. Instructional interventions, carefully considering how text chat is used in the classroom, may be the best way to push learners to make use of those aspects of the technology that encourage monitoring of production.

The primary purpose of the current study is to examine the role of two instructional interventions related to task implementation-task structure and language support-in promoting accurate and complex writing via text chat by L2 learners in a classroom setting. One of these, task structure, is drawn directly from Robinson's (2007) Triadic Componential Framework. The other, language support, is pre-task teaching and practice with linguistic forms. This was included because it reflected a common practice in the data collection context, so its impact on language learning opportunities was of interest. Specifically, the study aims to investigate the following questions. 
Table 1

Student characteristics.

\begin{tabular}{|c|c|c|}
\hline Characteristic & & \\
\hline \multirow[t]{2}{*}{ Gender } & Male & 68 \\
\hline & Female & 28 \\
\hline \multirow[t]{2}{*}{ Age } & Mean & 21.78 years \\
\hline & Range & $20-24$ years \\
\hline \multirow[t]{4}{*}{ L1 background } & Bahasa Malaysia & 77 \\
\hline & Chinese & 7 \\
\hline & Tamil & 4 \\
\hline & Indigenous languages of Malaysia & 8 \\
\hline \multirow[t]{2}{*}{ English language scores in the national exam } & Mean & 4.78 \\
\hline & Range & $4-6$ \\
\hline
\end{tabular}

1. Do task implementation conditions (task structure and language support) influence the accuracy of writing in peer L2 text chat?

2. Do task implementation conditions (task structure and language support) influence the complexity of writing in peer L2 text chat?

Both questions are directly relevant to the WLL agenda in exploring how teachers can influence learners' attention to the accuracy and complexity of their $\mathrm{CMC}$ writing via these two implementation decisions.

\section{Method}

\subsection{Participants and setting}

The study took place at a technical university in Malaysia which specializes in engineering. The university aims to produce graduates who are competent not only in engineering knowledge and skills, but also in communication skills, including communication in the L2 (English) in a range of contexts including CMC. Assessment tasks frequently require the students to negotiate engineering problems in scenarios that involve global electronic communication. For this reason, task design is an important consideration since the aim is to provide opportunities for English language competence and profession-specific communication skills to develop in tandem.

Ninety-six second-year electrical engineering undergraduates were randomly selected to participate in this study. Bahasa Malaysia was the native language for most of them. Table 1 summarizes the characteristics of the students.

The students were enrolled in a course on English for Professional Communication, the final, compulsory English language course for all students at the university. They had also completed three levels of English language courses in the previous semesters. Prior to this, they had learnt English language for about 11 years as a compulsory subject in primary and secondary school. The English language results in the national examination indicate that their English language proficiency was intermediate. ${ }^{1}$

All participants stayed in the university accommodation located within the campus area. Most of them used computers extensively for a variety of purposes, such as gaming, surfing the Internet for resources and chatting socially, and study. Overall, they were very comfortable with computers and text communication, especially in Bahasa Malaysia via computer.

\subsection{The Task}

The students participated in a 45-min interactive problem-solving task which required them to role play engineers in a multinational company. They were meeting in text chat to decide what type of electrical engineering software the company should adopt. Prior to the task, each student was given information on a software option to propose. They were asked to compare and contrast the software options and to reach consensus on the best software for the company based on set criteria (see Appendix A). They were given a recommendation sheet where they needed to rank the software (see Appendix D).

\footnotetext{
${ }^{1}$ The grade in the national examination is based on the following; $1=$ highest (high proficiency learners) $5=$ middle (intermediate proficiency learners) and $9=$ lowest (low proficiency learners). Most learners in this study obtained grade 4, 5, or 6 for the English language subject in the national examination. Reliability studies of this exam have found strong correlations with IELTS scores (cf. Rethinasamy and Chuah, 2011).
} 


\subsection{Task implementation variables}

Two task implementation variables were selected for this study. The first, task structure, forms part of Robinson's (2007) Triadic Componential framework. The second, language support, was implemented as a type of pre-task consciousness raising, similar to that used by Fiori (2005). While not explicitly included in Robinson's framework, it was designed to play a similar role as language-focused pre-task planning by pushing learners to explicitly consider language forms that would be useful as they carried out the task.

In the current study, task structure $(+/-\mathrm{TS})$ refers to the degree of structural support provided to learners while completing the task. Learners in the +TS condition were given written instructions on how to perform the task as well as a worksheet containing a comparison table which they were required to fill in as they discussed each software option (see Appendix C), which provided a framework for discussing the software. Learners in the low task structure (-TS) version of the task were given the basic task instructions, but no instructions on how to present the information and no comparison table. High task structure (+TS) is designed to guide task performance, and through that to reduce language processing burdens. On the other hand, learners without this guidance are required to attend to the procedures for completing the task and communicating meaning. Robinson (2007) describes a task with low structural support (-TS) as more complex because it demands a higher degree of simultaneous allocation of cognitive resources. This, he predicts, will result in less accurate and less complex language production.

Language support (+/-LS) was designed to be similar to pre-task language planning, but to also more closely reflect the way that language focus activities are used in this and other pedagogical settings. In the language support (+LS) condition, before learners began the task, they worked through a computer-based form-focused activity which targeted one of two linguistic forms: auxiliary or modal verbs. Half of the learners in this condition completed the auxiliary verbs exercise and the other half the modal verbs exercise. When these learners were subsequently placed in teams of four for the main writing task, each team of four included two learners who had completed the auxiliary verbs exercise and two who had completed the modal verbs exercise. This approach was taken to provide different team members with different linguistic expertise so as to facilitate collaborative focus on form during the task performance. The target forms were chosen based on items that were frequently discussed by learners in an earlier pilot of the task. Two different target forms were chosen to allow us to evaluate whether the language support materials increased the use of the targeted forms in text chat (these findings are reported in Nik et al., 2012).

For both forms, the language support involved three stages. First, learners read a dialogue based on the task which was seeded with the target form and were asked to underline each instance of this form. Second, the learners read a metalinguistic explanation of the form and completed a short multiple-choice grammar exercise. Third, they completed a blank-filling exercise. Immediate feedback was provided for each stage and learners were given a short written guide to using their target form, which was available on screen while they completed the task.

Language support is not specifically included in the Triadic Componential Framework (Robinson, 2007), but the pre-task language support activities used in this study were designed to resemble language-oriented pre-task planning which is in the framework. In both cases, learners take time before the task to consider forms that will be useful in carrying out that task. In the case of language support, learners are given materials to work through to suggest language items for them. Learners were asked to discuss samples of conversations on the task topic and to produce language similar to that required by the task (see Appendix B). While learners were not given access to the target task (as is usual in pre-task planning studies), the pretask language support condition still gave learners opportunities to prepare for their language use during the task, and was therefore predicted to have similar effects on language production. No language support (-LS) then is assumed to be more complex because it pushes learners to allocate their cognitive resources simultaneously to meaning and language form. This increased demand on learner attentional resources was predicted to lead to decreased accuracy and complexity.

\subsection{Design}

Four experimental conditions were set up, as outlined in Table 2. Learners were randomly assigned to one of these conditions, with 24 learners in each condition, divided into six teams of four.

The teams worked in a chatroom connected by networked computers, but they were scattered through the room so they could not communicate orally. They also used pseudonyms and did not know who the other team members were. The English class had a year-long expectation that learners would speak English in class, and they were reminded of this

Table 2

Task conditions.

\begin{tabular}{lll}
\hline & Low task structure (-TS) & High task structure (+TS) \\
\hline No language support & G1 & G2 \\
(-LS) & $n=24$ & $n=24$ \\
With language support & G3 & G4 \\
$(+$ LS $)$ & $n=24$ & $n=24$ \\
\hline
\end{tabular}


expectation before the task. They were also informed that their instructor would monitor their communication on the main terminal.

The course teacher and one of the researchers monitored the chat sessions using Renet ReLan software from the teacher's terminal. The students were only granted access to Google and mIRC (the chat client). Google consultation was allowed to enable students to look up unknown words or additional information on their software and was monitored. However, it was rarely used, with most students opting to stay in the chat, possibly because they were aware of teacher monitoring and of the time limit on the task.

\subsection{Data Collection}

Both the course instructor and one of the researchers monitored and captured each learner's screen from the main terminal using the classroom management system. Following the tasks, the chat exchanges were saved in log files, which served as the primary data source for this study.

Group interviews were also carried out face to face with three teams from each condition (48 learners in total) immediately after the chat session. The interviews were carried out in Bahasa Malaysia and translated to English by one of the researchers. The goal of the interviews was to gain information on learner perceptions of the task, their group's performance, and of the value of task-based text chat for language learning. Open-ended interview questions such as "What was going on here?" and "Why didn't you respond to this query?" were used. During the interviews the chat transcript from the respective team was projected to the screen, allowing the learners to view their discourse in its entirety. Additionally, the learners were given the opportunity to discuss interaction patterns they found to be interesting.

\subsection{Data Coding}

While the t-unit is a more commonly used unit of analysis of written language, it is typically applied to more canonical forms of writing such as an individually written essay. As we noted earlier, CMC is a new, highly interactive form of writing that requires alternative units of analysis that capture its unique qualities. For this reason, we chose the Analysis of Speech (AS)-unit as a unit of analysis following Foster, Tonkyn, and Wigglesworth's (2000) contention that it is the most appropriate unit for written or spoken communication in settings with rapid information exchange. Foster, Tonkyn, and Wigglesworth (2000) define the AS-unit as

. . . . a a single speakers' utterance consisting of an independent clause, or sub-clausal unit, together with any subordinate clause(s) associated with either. An independent sub-clausal unit will consist of: either one or more phrases which can be elaborated to a full clause by means of recovery of ellipted elements from the context of the discourse or situation OR $a$ minor utterance, which will be defined as one of the class of 'Irregular sentences' or 'Non-sentences' identified by Quirk et al. (1985: 838-53). A subordinate clause will consist minimally of a finite or non-finite Verb element plus at least one other clause element (Subject, Object, Complement or Adverbial). (pp. 365-366)

The use of AS-units was modified slightly to account for the way punctuation is used in CMC as a stand-in for intonation. In interview sessions, participants consistently commented that they used punctuation to mark intonation and pausing. Since both pausing and intonation curves distinguish AS-units in oral production, we modified the coding of AS-units to account for the use of punctuation in CMC as a proxy for prosody. Table 3 exemplifies AS-unit coding. All data is from the current study.

Various methods have been used to measure the accuracy of language production in spoken and written L2 discourse. Several researchers have noted the importance of including both specific and general measures of accuracy (e.g., Housen \& Kuiken, 2009; Robinson \& Gilabert, 2007). This study included three measures of accuracy: mean errors per AS-unit (general) and target-like use of auxiliary verbs and modal verbs (specific).

Following Pallotti (2009), complexity was measured both through structural and lexical complexity. Similar to other studies of task complexity (e.g., Michel, Kuiken, \& Vedder, 2007; Tavakoli \& Skehan, 2005), structural complexity was measured through embeddings, using clauses per AS-unit as the measure. Because Norris and Ortega (2009) recommend multiple measures of complexity, we also measured words/turn as a more global measure of utterance complexity. For this

Table 3

AS-units.

\begin{tabular}{ll}
\hline Punctuation & Example \\
\hline Period (.) & I i need more information about MATLAB. I Can u xplain? I \\
More than one dot $(\ldots)$ & I it animates various automation tech... I this includes PLC and etc. I \\
Comma (.) & I before we decide the product, I consider its practicalityy utilization and cost I \\
Question mark (?) & I Shall we make our own ranking? I then we decide I \\
Hyphen (-) & I let me introduce my sofware-I it is called OrCAD I \\
Colon (:) & I fill in utilization colmn: I the specs include graphic editor, symbol editor, tex editor and complier I \\
\hline
\end{tabular}

Note: Following Foster et al. (2000), AS-unit boundary is marked by an upright slash I. 
measure, turns, rather than AS-units were used as an index of contribution length. Two measures of lexical complexity were used: lexical frequency and the Guiraud index. Nation's lexical frequency profiler (LFP) was used to determine how many words learners used that fell outside the 1000 most frequent words, based on the British National Corpus word frequency list used for the LFP (Nation, 2004). In order to use the profiler, the chat transcripts first had to be revised for compatibility between the existing BNC wordlists and the words from the text chat transcripts. The transcripts were edited to remove spelling inconsistencies caused by typos, by text chat jargon (e.g., b4 instead of before), by idiomatic spellings (e.g., evrybdy instead of everybody), and by emphatic grapheme duplication (errrr instead of er), and by missing spaces between words (e.g., veryexpensive to very expensive). After running the profiler, for each learner the percentage of less frequent words was calculated. The Guiraud index of lexical richness was selected rather than a type/token ratio to correct for effects of text length (Vermeer, 2000). The Guiraud index was selected over $D$ as a measure of lexical richness because of text length (while the transcripts were quite long, the amount of text produced by each individual learner was only a fraction of the length). The Guiraud index is computed as the ratio of types to the square root of tokens in a text.

Inter-rater reliability was assessed for all coding. The second rater coded $25 \%$ of the data. The agreement reached $90 \%$. Based on this, it was determined that one of the researchers could independently code the rest of the data. This researcher also recoded $25 \%$ of the data following a one-month interval, and intra-rater reliability reached $96 \%$, indicating a high level of coding consistency.

\subsection{Analysis}

Three MANOVA models were used to analyze the quantitative data in this study. The first two models examined individual measures of accuracy and complexity $(n=96)$. The third model was used to analyze team results for the participation analysis $(n=24)$. In both cases, Hotelling's Trace was the chosen significance test because the groups were formed based on independent variables. When multivariate tests indicated significant differences, univariate $F$ tests were used to locate the source(s) of those differences.

A Box $M$ test was carried out for each MANOVA to see if the assumption of homogeneity of the covariance matrix was met. If the $p$ value was less than 0.001 this was taken to imply that the assumption was not met. Nevertheless, as size was equal and consistent across all conditions, the results of multivariate $F$ tests were still used even if this assumption was not met. Additionally, since the Box $M$ test is quite robust to departures from the assumption of equality of covariance matrices, the univariate $F$ test can still be used even if the covariances are different.

\section{Results}

\subsection{Task implementation conditions and accuracy of text chat production}

The descriptive statistics for the measures of accuracy measures are displayed in Table 4.

Scores for accuracy measures were submitted to MANOVA analysis to determine if the groups differed significantly with regard to the accuracy of their language production. This is reported in Table 5.

The results showed that overall differences between groups were statistically significant, both for task structure $(p=0.002)$ and language support $(p<0.0001)$. The effect size for task structure was small $\left(\eta_{\mathrm{p}}{ }^{2}=0.15\right)$, while the effect size for

\section{Table 4}

Accuracy: descriptive statistics.

\begin{tabular}{|c|c|c|c|c|c|}
\hline & TS & LS & Mean & SD & $N$ \\
\hline \multirow[t]{6}{*}{ Errors/AS-unit } & $-\mathrm{TS}$ & $-\mathrm{LS}$ & 0.4 & 0.17 & 24 \\
\hline & & $+\mathrm{LS}$ & 0.11 & 0.05 & 24 \\
\hline & & Total & 0.25 & 0.19 & 48 \\
\hline & -TS & $-\mathrm{LS}$ & 0.31 & 0.16 & 24 \\
\hline & & $+\mathrm{LS}$ & 0.04 & 0.03 & 24 \\
\hline & & Total & 0.18 & 0.17 & 48 \\
\hline \multirow[t]{6}{*}{ Target-like use of auxiliary verbs } & $-\mathrm{TS}$ & $-\mathrm{LS}$ & 52.83 & 24.83 & 24 \\
\hline & & $+\mathrm{LS}$ & 73.94 & 16.98 & 24 \\
\hline & & Total & 63.38 & 23.59 & 48 \\
\hline & $+\mathrm{TS}$ & $-\mathrm{LS}$ & 52.34 & 22.88 & 24 \\
\hline & & $+\mathrm{LS}$ & 92.83 & 8.97 & 24 \\
\hline & & Total & 72.58 & 26.72 & 48 \\
\hline \multirow[t]{6}{*}{ Target-like use of modal verbs } & $-\mathrm{TS}$ & $-\mathrm{LS}$ & 74.85 & 15.62 & 24 \\
\hline & & $+\mathrm{LS}$ & 88.08 & 22.15 & 24 \\
\hline & & Total & 81.46 & 20.11 & 48 \\
\hline & $+\mathrm{TS}$ & $-\mathrm{LS}$ & 79.44 & 23.49 & 24 \\
\hline & & $+\mathrm{LS}$ & 99.3 & 3.4 & 24 \\
\hline & & Total & 89.37 & 19.41 & 48 \\
\hline
\end{tabular}


Table 5

Accuracy: multivariate tests.

\begin{tabular}{|c|c|c|c|c|c|c|c|c|}
\hline \multicolumn{9}{|c|}{ Multivariate Test $^{\mathrm{c}}$} \\
\hline & & Value & $F$ & Hypothesis df & Error df & $p$ & $\eta_{\mathrm{p}}^{2}$ & Observed power ${ }^{\mathrm{a}}$ \\
\hline TS & Hotelling's & 0.18 & $5.42^{\mathrm{b}}$ & 3.00 & 90.00 & 0.002 & 0.15 & 0.93 \\
\hline LS & Trace & 1.83 & $54.93^{b}$ & 3.00 & 90.00 & $<0.0001$ & 0.65 & 1.00 \\
\hline $\mathrm{TS} \times \mathrm{LS}$ & $\begin{array}{l}\text { Hotelling's } \\
\text { Trace } \\
\text { Hotelling's } \\
\text { Trace }\end{array}$ & 0.11 & $3.21^{b}$ & 4.00 & 90.00 & 0.027 & 0.10 & 0.72 \\
\hline
\end{tabular}

Note: ${ }^{*} p \leq 0.05$

${ }^{\mathrm{a} C o m p u t e d}$ using alpha $=0.05$.

${ }^{\mathrm{b}}$ Exact statistic.

${ }^{\mathrm{c}}$ Design: intercept $+\mathrm{TS}+\mathrm{LS}+\mathrm{TS} \times \mathrm{LS}$.

language support was medium $\left(\eta_{\mathrm{p}}{ }^{2}=0.65\right)$. The interaction between task structure and language support was also significant $(p=0.027)$, but the effect size was very weak $\left(\eta_{\mathrm{p}}{ }^{2}=0.10\right)$. This indicated that analyses of between-subject effects were necessary. These are presented in Table 6.

Both task structure and language support were significantly related to the number of errors per AS-unit. Learners who performed the more structured task (+TS) had greater accuracy $(M=0.18, \mathrm{SD}=0.17)$ than learners whose task was less structured $(-\mathrm{TS})(M=0.25, \mathrm{SD}=0.19)$. Although the effect was significant, the difference was relatively small $\left(\eta_{\mathrm{p}}{ }^{2}=0.10\right)$.

Learners who received language support ( $+\mathrm{LS})$ had a lower error rate $(M=0.08, \mathrm{SD}=0.05)$ than learners who did not $(-\mathrm{LS})$ $(M=0.35, \mathrm{SD}=0.17)$. There was a moderate effect size $\left(\eta_{\mathrm{p}}{ }^{2}=0.57\right)$. The $F$-value of the interaction effect was not significant, indicating that the effects of language support and task structure are independent of each other. This means that whether learners received only language support or only performed a more structured task, their language errors were still reduced.

The univariate between-subjects test again shows that both task structure and language support were significantly related to the percentage of target-like use of auxiliary verbs. There was also an interaction effect, with a medium effect size $\left(\eta_{\mathrm{p}}{ }^{2}=0.06\right)$. Thus, for learners provided with language support $(+\mathrm{LS})$, those who performed the more structured task (+TS) used more target-like auxiliary verbs $(M=92.83, \mathrm{SD}=8.97)$ than learners who performed the less structured task ( $-\mathrm{TS})$ $(M=73.94, \mathrm{SD}=16.98)$. In contrast, for learners not provided with language support $(-\mathrm{LS})$, the amount of task structure did not have a significant effect on this language feature.

Both task structure and language support had a significant effect on the target-like use of modal verbs, although in this case there was no significant interaction. Similar to the general accuracy measurement, learners provided with language support (+LS) produced a higher percentage of target-like use of modal verbs $(M=93.69, \mathrm{SD}=16.67)$ than learners without this support $(-\mathrm{LS})(M=77.14, \mathrm{SD}=19.87)$ but the effect size was small $\left(\eta_{\mathrm{p}}{ }^{2}=0.18\right)$. Learners who performed the more structured task (+TS) also produced a higher percentage of target-like use of modal verbs $(M=89.37, \mathrm{SD}=19.40)$ than learners who performed the less structured task $(-\mathrm{TS})(M=81.46, \mathrm{SD}=20.10)$. Again, the effect size was extremely small $\left(\eta_{\mathrm{p}}{ }^{2}=0.05\right)$.

Overall, and in line with Robinson's (2007) predictions, the accuracy analysis indicates that learners who completed the task under less complex conditions (+TS) produced more accurate language than learners who did so under more complex conditions. Language support played a similar role.

Table 6

Univariate results for accuracy.

\begin{tabular}{|c|c|c|c|c|c|c|c|c|}
\hline & & Type III sum of squares & df & Mean square & $F$ & $p$ & $\eta_{\mathrm{p}}{ }^{2}$ & Observed power $^{\mathrm{a}}$ \\
\hline \multirow[t]{3}{*}{ Errors/AS-unit } & TS & 0.15 & 1 & 0.15 & 9.89 & 0.002 & 0.1 & 0.87 \\
\hline & LS & 1.84 & 1 & 1.84 & 124.18 & $<0.0001$ & 0.6 & 1 \\
\hline & $\mathrm{TS} \times \mathrm{LS}$ & 0 & 1 & 0 & 0.3 & 0.585 & 0 & 0.08 \\
\hline \multirow[t]{3}{*}{ Target-like use of auxiliary verbs } & TS & 2030.97 & 1 & 2030.97 & 5.38 & 0.023 & 0.05 & 0.63 \\
\hline & LS & 22763.04 & 1 & 22763.04 & 60.33 & $<0.0001$ & 0.4 & 1 \\
\hline & $\mathrm{TS} \times \mathrm{LS}$ & 2253.86 & 1 & 2253.86 & 5.97 & 0.016 & 0.06 & 0.68 \\
\hline \multirow[t]{3}{*}{ Target-like use of modal verbs } & TS & 1501.62 & 1 & 1501.62 & 4.63 & 0.034 & 0.05 & 0.57 \\
\hline & LS & 6572.5 & 1 & 6572.5 & 20.25 & $<0.0001$ & 0.18 & 0.99 \\
\hline & $\mathrm{TS} \times \mathrm{LS}$ & 264.46 & 1 & 264.46 & 0.81 & 0.369 & 0.01 & 0.14 \\
\hline
\end{tabular}

Note: ${ }^{*} p \leq 0.05$.

a Computed using alpha $=0.05$. 
Table 7

Complexity: descriptive statistics.

\begin{tabular}{|c|c|c|c|c|c|}
\hline & TS & LS & Mean & SD & $N$ \\
\hline \multirow[t]{6}{*}{ Clauses/AS-unit } & $-\mathrm{TS}$ & $-\mathrm{LS}$ & 0.73 & 0.14 & 24 \\
\hline & & $+\mathrm{LS}$ & 0.57 & 0.18 & 24 \\
\hline & & Total & 0.65 & 0.18 & 48 \\
\hline & $+\mathrm{TS}$ & $-\mathrm{LS}$ & 0.63 & 0.13 & 24 \\
\hline & & $+\mathrm{LS}$ & 0.59 & 0.15 & 24 \\
\hline & & Total & 0.61 & 0.14 & 48 \\
\hline \multirow[t]{6}{*}{ Words/turn } & $-\mathrm{TS}$ & $-\mathrm{LS}$ & 5.53 & 1.36 & 24 \\
\hline & & $+\mathrm{LS}$ & 3.81 & 1.23 & 24 \\
\hline & & Total & 4.67 & 1.55 & 48 \\
\hline & $+\mathrm{TS}$ & $-\mathrm{LS}$ & 4.97 & 1.43 & 24 \\
\hline & & $+\mathrm{LS}$ & 4.03 & 0.93 & 24 \\
\hline & & Total & 4.5 & 1.29 & 48 \\
\hline \multirow[t]{6}{*}{ \% Less frequent words } & $-\mathrm{TS}$ & $-\mathrm{LS}$ & 20.68 & 4.61 & 24 \\
\hline & & $+\mathrm{LS}$ & 18.1 & 3.55 & 24 \\
\hline & & Total & 19.39 & 4.27 & 48 \\
\hline & $+\mathrm{TS}$ & $-\mathrm{LS}$ & 22.14 & 4.46 & 24 \\
\hline & & $+\mathrm{LS}$ & 17.64 & 3.72 & 24 \\
\hline & & Total & 19.89 & 4.66 & 48 \\
\hline \multirow[t]{6}{*}{ Guiraud index } & $-\mathrm{TS}$ & $-\mathrm{LS}$ & 8.2 & 0.92 & 24 \\
\hline & & $+\mathrm{LS}$ & 8.56 & 2.06 & 24 \\
\hline & & Total & 8.38 & 1.59 & 48 \\
\hline & $+\mathrm{TS}$ & $-\mathrm{LS}$ & 8.6 & 0.72 & 24 \\
\hline & & $+\mathrm{LS}$ & 7.97 & 0.8 & 24 \\
\hline & & Total & 8.29 & 0.82 & 48 \\
\hline
\end{tabular}

\subsection{Task implementation conditions and complexity of text chat production}

Descriptive statistics for complexity measures are displayed in Table 7.

An individual-based MANOVA model was also used to determine if the groups differed significantly in the complexity of their output. As the measures were correlated, only one model was used. Three measures of linguistic complexity were used: clauses/AS-unit, percentage of less frequent vocabulary, and the Guiraud index of lexical richness. The three measures for complexity were assumed to be correlated with each other, even though one was specific for syntactic complexity while the other two were lexical complexity measures. Therefore, the data were run in the same MANOVA to test multiple dependent variables simultaneously while keeping track of their correlation with each other. Additionally, it can protect against Type I errors that might occur if multiple ANOVAs were conducted independently. Table 8 reports the results.

The Hotelling's Trace multivariate test of the effect of task structure on the linguistic complexity variables was not significant $(p=0.656)$, which indicates that the effects of low and high task structure were similar and, therefore, further analysis on the effect of task structure on the complexity variables was not needed. However, the test of the effect of language support on the dependent variables was statistically significant $(p<0.0001)$, although with rather a weak effect $\left(\eta_{\mathrm{p}}{ }^{2}=0.27\right)$. This test also returns a significant interaction effect $(p=0.021)$ although the effect size was again weak $\left(\eta_{\mathrm{p}}{ }^{2}=0.10\right)$. Univariate analyses of between-subjects effects for language support on the dependent variables, and the interaction effects are presented in Table 9.

Table 8

Complexity: multivariate tests.

\begin{tabular}{|c|c|c|c|c|c|c|c|c|}
\hline \multicolumn{9}{|c|}{ Multivariate tests ${ }^{\mathrm{c}}$} \\
\hline & & Value & $F$ & Hypothesis df & Error df & $p$ & $\eta_{\mathrm{p}}{ }^{2}$ & Observed power ${ }^{\mathrm{a}}$ \\
\hline TS & Hotelling's & 0.02 & $0.54^{\mathrm{b}}$ & 3.00 & 90.00 & 0.656 & 0.02 & 0.16 \\
\hline LS & Trace & 0.37 & $110.9^{b}$ & 3.00 & 90.00 & $<0.0001$ & 0.27 & 1.00 \\
\hline $\mathrm{TS} \times \mathrm{LS}$ & $\begin{array}{l}\text { Hotelling's } \\
\text { Trace } \\
\text { Hotelling's } \\
\text { Trace }\end{array}$ & 0.11 & $3.41^{\mathrm{b}}$ & 3.00 & 90.00 & 0.021 & 0.10 & 0.75 \\
\hline
\end{tabular}

Note: ${ }^{*} p \leq 0.05$.

a Computed using alpha $=0.05$.

b Exact statistic.

c Design: intercept $+\mathrm{TS}+\mathrm{LS}+\mathrm{TS} \times \mathrm{LS}$. 
Table 9

Complexity: between-subjects effects.

\begin{tabular}{|c|c|c|c|c|c|c|c|c|}
\hline \multicolumn{9}{|c|}{ Test of between-subjects effects } \\
\hline & & Type III sum of squares & $\mathrm{df}$ & Mean square & $F$ & $P$ & $\eta_{\mathrm{p}}^{2}$ & Observed power $^{\mathrm{a}}$ \\
\hline \multirow[t]{3}{*}{ Clauses/AS-unit } & TS & 0.03 & 1 & 0.03 & 1.39 & 0.241 & 0.01 & 0.21 \\
\hline & LS & 0.25 & 1 & 0.25 & 10.73 & 0.001 & 0.1 & 0.9 \\
\hline & $\mathrm{TS} \times \mathrm{LS}$ & 0.1 & 1 & 0.1 & 4.28 & 0.041 & 0.04 & 0.53 \\
\hline \multirow[t]{3}{*}{ Words/turn } & TS & 0.7 & 1 & 0.7 & 0.45 & 0.505 & 0.01 & 0.1 \\
\hline & LS & 42.52 & 1 & 42.52 & 27.04 & $<0.0001$ & 0.23 & 1 \\
\hline & $\mathrm{TS} \times \mathrm{LS}$ & 3.6 & 1 & 3.6 & 2.29 & 0.134 & 0.02 & 0.32 \\
\hline \multirow[t]{3}{*}{ \% Less frequent words } & TS & 6.12 & 1 & 6.12 & 0.36 & 0.549 & 0 & 0.09 \\
\hline & LS & 302.07 & 1 & 302.07 & 17.88 & $<0.0001$ & 0.16 & 0.99 \\
\hline & $\mathrm{TS} \times \mathrm{LS}$ & 21.84 & 1 & 21.84 & 1.29 & 0.258 & 0.01 & 0.2 \\
\hline \multirow[t]{3}{*}{ Guiraud index } & TS & 0.21 & 1 & 0.21 & 0.13 & 0.715 & 0 & 0.06 \\
\hline & LS & 0.44 & 1 & 0.44 & 0.28 & 0.599 & 0 & 0.08 \\
\hline & $\mathrm{TS} \times \mathrm{LS}$ & 5.99 & 1 & 5.99 & 3.82 & 0.054 & 0.04 & 0.49 \\
\hline
\end{tabular}

Note: ${ }^{*} p \leq 0.05$.

a Computed using alpha $=0.05$.

For syntactic complexity measured by clauses/AS-unit, the interaction between task structure and language support was significant, though the effect size was very weak $\left(\eta_{\mathrm{p}}{ }^{2}=0.04\right)$. For learners who performed the more structured task (+TS), those with no language support $(-\mathrm{LS})$ produced more complex syntactic structures $(M=0.63, \mathrm{SD}=0.13)$ than those with language support $(+\mathrm{LS})(M=0.59, \mathrm{SD}=0.15)$. There was a significant effect of language support for words/turn, with learners in the no language support $(-\mathrm{LS})$ condition producing significantly more words $(M=5.25$, SD $=1.41)$ than those in the language support $(+\mathrm{LS})$ condition $(M=3.92, \mathrm{SD}=1.08)$. In each case, language support seemed to undermine syntactic complexity.

There was a significant language support effect on the use of low frequency vocabulary. Learners without language support $(-\mathrm{LS})$ used significantly more low frequency words $(M=21.41, \mathrm{SD}=4.55)$ than those with language support $(+\mathrm{LS})$ $(M=17.86, \mathrm{SD}=3.60)$. However, the difference was small $\left(\eta_{\mathrm{p}}^{2}=0.16\right)$. There was no interaction effect for the use of low frequency vocabulary.

A significant interaction was found for the Giraud index. However, the effect is extremely small $\left(\eta_{\mathrm{p}}{ }^{2}=0.04\right)$. Learners performing the less structured task with language support $(M=8.56, \mathrm{SD}=2.56)$ or the more structured task without language support $(M=8.60, \mathrm{SD}=0.72)$ both produced more lexically rich language than learners having neither $(M=8.20, \mathrm{SD}=0.92)$ or both $(M=7.97, \mathrm{SD}=0.80)$. The similarity of the means across all four task conditions implies that this effect, while significant, may not be meaningful.

Overall, the complexity analysis showed task structure had minimal effects on the complexity of language production, while providing language support actually decreased the complexity of learning language production. However, all effect sizes were small.

\section{Discussion}

The purpose of this study was to extend research on task complexity to writing via CMC and in so doing to contribute to the WLL research agenda. CMC is integral to the future of writing, and text chat, as the most speech-like of the new ways of writing, is one pathway into that future. To understand how people write for learning, in both L1 and L2, we need to think about the full range of writing modalities, not just the canonical individually written paragraph or essay. While a significant body of research has considered the role of task complexity in language production in face-to-face communication and in pen-and-paper writing, very little research has examined complexity in writing via CMC. By showing how particular task factors influence the quality of language produced by learners in text chat, the research reported here can help teachers use text chat more effectively to promote specific language learning aims.

Predictions from the Cognition Hypothesis on how task complexity factors open up or constrain language learning opportunities through tasks provide the theoretical framework for this study. In the Cognition Hypothesis, Robinson (2007) predicts that making tasks more complex by increasing the resource-dispersing demands of the task will require learners to divert attention from language form to, for example, procedural matters. This, in turn, will lead to less accurate and less complex language production. Our findings partly bear this out. The overall pattern of results for language accuracy was that learners who performed more complex tasks (made more complex by either reducing task structure or not providing language support) produced less accurate writing. However, making tasks more complex through providing less task structure had very little effect on the complexity of their writing. While language support is not part of the Cognition Hypothesis, its effect here was similar, actually decreasing the complexity of the written production. We now discuss these findings in more detail. 


\subsection{Accuracy}

The chat transcripts illustrate how reducing the cognitive complexity of the tasks may have pushed learners to attend to linguistic accuracy. ${ }^{2}$ Extract 1 provides an example from learners in the +TS condition who use pre-set categories in the +TS material to structure their performance, and, in the process, to pay particular attention to accuracy. In line 3, Da uses an incorrect form of the main verb after the modal may which she then corrects in line 5, as does Min in line 6 ( simultaneously, it appears). In all extracts, the transcripts are reproduced as the participants created them. No transcription symbols have been added.

Extract 1

\begin{tabular}{lll}
\hline 1 & Min & Discuss the nxt colymn- utilization- do u guys agree? \\
2 & Nor & Shoot- who shud start first? \\
3 & Da & Nan may starts first: discuss utilization ok \\
4 & Nan & Mine: compatible with microsoft \\
5 & Da & Nan may start first ${ }^{3}$ \\
6 & Min & Da- may start- w/out s! \\
\hline
\end{tabular}

During the post-task interview, these learners claimed that the +TS material helped guide their performance and focus their attention on their written output. As Min recalled, when asked about the +TS material:

When I received sheet $B$, I compared the information in it with the task instruction received earlier. Then I knew that I should promote my software based on the column in sheet B so that our team could discuss the task systematically. My assumption was true. During the task performance, for example, if it was Da's turn everybody waited until she posted her message on the screen. We knew exactly in which column in Sheet B the message should appear. This means we did not have much trouble understanding the gist of the message, and I think that made us more attentive to the language our teammates used. I mean it allowed us to be more conscious of others' language expressions.

Min's explanation of his task experience is strikingly similar to Robinson's (2005) account of the effect of simplifying tasks using resource-dispersing factors. Implementing tasks in this way frees up cognitive resources from managing the content making these resources available to monitor written language expression. This may be particularly important when performing tasks via text chat where the discourse is characterized by interrupted turns and overlaps which make managing the flow of communication particularly difficult (Smith, 2003). In this context, an implementation option such as providing a more structured task plan may be particularly effective in reducing the cognitive load of the task.

Adding pre-task language support also increased the accuracy of writing, both by providing language models for learners to use in the task and by raising learners' consciousness of accuracy. Extract 2 exemplifies how learners modelled the targetlike use of auxiliary verb based on the +LS material. Here, in line 1, Jep uses a non-target-like verb phrase are decided which is pointed out by Sam in line 3 and corrected in line 5.

\section{Extract 2}

\begin{tabular}{lll}
\hline 1 & Jep & We are decided Orcad rite? \\
2 & Bugo & Orrcad? \\
3 & Sam & Not are decided, man! \\
4 & Jep & Yes orcad \\
5 & Sam & Have decided \\
6 & Jep & What?? \\
7 & Tan & Yerp Jep- u shud write- we have decided \\
8 & Bugo & Read your notes! 4 goodness sake! \\
9 & Jep & Ok it is wrong. . . but gimme good marks nyeh \\
\hline
\end{tabular}

While the language support materials focused on the target-like use of auxiliary and modal verbs, learners who used these materials appeared more conscious of the overall accuracy of their language and consequently produced more globally accurate writing. We see this in Extract 3 where learners in the +LS group attended to a word order problem.

\footnotetext{
2 The students selected pseudonyms for the tasks to discourage oral communication around the room. Their self-selected pseudonyms are preserved in all transcripts.

3 The symbol $\left({ }^{*}\right)$ used in this example is original to the transcript. The student has used it to draw attention to her self-correction of her earlier turn.
} 
Extract 3

\begin{tabular}{lll}
\hline 1 & Hus & I think is better matlab \\
2 & Abidin & Thats incorrect \\
3 & Hus & What do u mean? we agreed matlab! \\
4 & Gimbus & No.. he means your writing \\
5 & Abidin & Hus- ** $\mathrm{i}$ think matlab is better \\
6 & Sabar & Lol ... direct translantion frm bm ${ }^{4}$ \\
7 & Hus & A $^{\wedge}$ Will b careful nxt time \\
8 & Gimbus & Must use corect English $\mathrm{k}$ \\
\hline
\end{tabular}

An earlier study of the task-based text chat communication of similar learners (Nik \& Adams, 2009) found comparable use of Bahasa Malaysia syntax as a communication strategy. However, the learners in that study were not given pre-task language activities and did not comment on or correct each other's language use. This suggests that providing language support even on limited forms may shift learner perceptions of the task as language practice, pushing them to use the writing practice to monitor the accuracy of their language production. As Manchón (2012b) has pointed out, this collaborative attention to form in writing suggests that the writing activity may promote learning of language forms. Although the communicative outcome of the tasks did not appear to suffer from this increased focus on form, we did not design the research to address this issue and so it remains an interesting question to pursue in a future study.

These findings suggest two paths for focusing learners on the accuracy of the language production in text chat, either by manipulating the characteristics of the task (as in task support) or by explicitly raising attention (as in language support). Increasing attention to language accuracy through explicit teaching (+LS) produced a larger effect in terms of promoting accurate production and may be more effective for pushing students to monitor their written production. However, the alternative of manipulating the task structure by providing more procedural support (+TS) may be less likely to disrupt learner focus on communication of meaning. Because text chat provides learners with opportunities to participate in real time written communication, it may raise their awareness of written production as a means of interpersonal communication in L2. Thus, we would argue that promoting accuracy through task manipulations such as providing more structural support may be less likely to disrupt the communicative focus of the discourse.

\subsection{Complexity}

While the findings for accuracy largely support the predictions of the Cognition Hypothesis, the findings for complexity overall do not. Increased task complexity along resource-dispersing dimensions led to more complex writing, particularly when no pre-task language support was given. This suggests that the increase in task complexity did not divert learners' attention from both accuracy and complexity; rather, it may have pushed them into a trade-off situation where they needed to choose to prioritize one over the other. In a post-task interview, one of the learners in the +LS condition makes exactly this point:

I wanted to make sure that I used correct grammar. If I spent time trying to use difficult words or words that I don't normally use during conversation, I'm afraid I would end up producing many grammatical errors because I couldn't do both at the same time. It's difficult for me.

Learners provided with language support may have been primed to prioritize accuracy over complexity since the language support focused on two linguistic forms (auxiliary and modal verbs) rather than on syntactic or lexical complexity. Indeed, a learner who completed the task in the +LS condition noted just how much of an influence this support had:

In my opinion, there could be many reasons why we focused on grammar during the chat session. First, my teammates kept on reminding us about the use of correct grammar. Second, we became more aware of what we wrote because of the language exercise we did earlier. As seen here, when someone produced errors, one of us would notice the errors. However, I think sometimes we got too conscious of our grammar; we disregarded other language aspects. I mean, we forgot that grammar is not the only thing that makes you an effective speaker or writer of English language!

The written nature of text chat may also have contributed to this effect. During the post-task interviews, most learners who received language support agreed that they were conscious of their own and others' writing because they were able to view messages on the screen. However, because of the speed of exchange of online text messages, they tended to reply using recycled high-frequency words according to the comments of one of the learners in the +LS condition:

Learning via chatting is a good practice for us because we can see where our language problems are on the screen. In face-toface, we can only detect the most obvious problem. However, in chatting, sometimes you feel the need to keep up with the rapid information exchange. Because I wanted to be quick in responding, I used simple words. What I mean is, I used everyday words.

This echoes earlier findings about the effect of the writing-like aspects of text chat as well as the emerging visual transcript of the communication which enables learners to focus on their language (Sanders, 2006; Deusen-Scholl, Frei, \&

\footnotetext{
${ }^{4}$ Note: "bm" = Bahasa Malaysia.
} 
Dixon, 2005). While this may push learners to make form-meaning connections in text chat (Doughty \& Long, 2003), factors such as the speed of text exchange in text chat may also reduce opportunities to attend to linguistic complexity compared to pen-and-paper collaborative writing.

The issues addressed in this discussion of the results clearly extend beyond the Cognition Hypothesis (Robinson, 2001) to themes emerging from the broader WLL research agenda, including attention to form in writing, the contribution of collaborative writing, and the impact of the pace and permanence of writing on language learning (cf. Manchón, 2012a,b; Ortega, 2012; Williams, 2012) as discussed above. A further issue, of writer identity, warrants brief comment as these learners were engaged in language learning for professional purposes. The educational identity of these learners (future engineers) might have influenced how they processed or approached writing, their use of CMC, and awareness of form. The students who participated in this study were keenly aware of the importance of a high standard of English for securing employment in their profession and indeed for working in this profession since English is widely used in industry in Malaysia. As future engineers, they are also aware of the likelihood of communicating-orally and in writing-with bosses or other engineers for whom English is a first language. Furthermore, widespread publicity in Malaysia points to the poor English communication skills of graduates as being a major factor in difficulties finding employment. Their engagement in the task and response to the task conditions may be related to their quite uniform reasons for learning English and the perceived relevance of the task to their future careers.

\section{Conclusion}

This study provides further insights into the pedagogic use of tasks in writing via text chat in language learning settings. Our findings suggest that, in the absence of paralinguistic features of face-to-face communication, carefully structuring and supporting task performance in text chat may reduce online processing demands and thus free up processing capacity for learners to attend to linguistic aspects of their written language production. When this is achieved through adding a deliberate pre-writing focus on a relevant grammatical form our study showed clear evidence of learners collaboratively and explicitly drawing attention to errors relating to this form in their CMC writing and producing more accurate writing as a result. However, the extent to which this may distract learners from the communicative purpose of the writing and compromise task outcomes was not investigated. Since providing additional structural support for the task performance also led to more accurate writing and did so without compromising the communicative focus of the task, this more indirect way of encouraging a focus on accuracy may be a preferred option for many teachers.

Caution is advised in generalizing these results, foremost because the sample size was relatively small for the $2 \times 2$ design used in the study. Note that the power analysis of each MANOVA test fell below 0.8. Increasing sample sizes in future studies of text chat that manipulate multiple variables would enhance our confidence in the findings. While this study examined two factors in how tasks are used, only one was drawn from the Cognition Hypothesis. To validate (or further question) the reach of the Cognition Hypothesis to tasks carried out in text chat and other computer-based writing, it would be valuable to examine other variables from the Cognition Hypothesis, including resource-directing variables which have rarely been examined in CMC studies. While a text-based communication medium was chosen for this study, other CMC text-based platforms, such as blogs and wikis, more closely resemble traditional writing. Understanding the role of task structure and language support in promoting accurate language use in these writing contexts would help us understand how much interactive communication in text chat shares with traditional monologic writing. Future research should also consider the gap between language practice and language learning in writing context. How much attention to accuracy in text chat situations may help learners increase their mastery of linguistic forms in other contexts is uncertain. Understanding this connection may shed more light on the role of task-based production in long-term learning.

This study shows that careful consideration of how CMC tasks are implemented may help learners widen their perception of how to communicate in text chat and how to maximize language learning opportunities through this writing medium, thus breaking the pattern of text chat as a site for simplified language use. Specifically, by carefully designing and implementing CMC-based writing tasks to meet specific pedagogical aims, teachers can foster the opportunities available to learners to focus on the complexity and accuracy of their written production. For these reasons, and given favorable instructional circumstances, the unique characteristics of text chat can make it a positive site for writing-to-learn. Because teachers generally make the decisions concerning how a task is used in their classrooms, they play a key role in shaping the quality of learning opportunities in text chat. As Ortega (2012) argues, "the inclusion of more central and richer roles for teachers and tasks in future research agendas would be a noteworthy addition to efforts at understanding instructional interfaces (between L2 writing and SLA research)" (p. 411).

\section{Appendix A.}

\section{Examples of software criteria for Student A \\ Student A \\ Background}

This is a virtual meeting conducted via a chat room on Tuesday, 21st March 2006, at 14:00:00. GMT. Note that the attendees are located at different time zones. A-An engineer based in Kuala Lumpur (Wed 14:00:00 GMT).B-An engineer 
based in Tokyo (Wed 15:00:00 GMT).C-An engineer based in Bangkok (Wed 13:00:00 GMT).D-An engineer based in Helsinki (Wed 09:00:00 GMT).

You are an electrical engineer at a multinational company, Diamond Circuit Ltd. You are based at its headquarters in Kuala Lumpur. The company has other branches located at Bangkok, Tokyo, and Helsinki. Since the company is growing, it has to be equipped with more advanced facilities, among which are various types of electrical engineering software for electrical designs, simulations and analyses as well as for technical diagramming and drafting. Other possible benefits for the company of having more and up-to-date software are to ensure the company incorporates new technologies in a rapidly growing range of applications, to integrate current computer systems with new and more mobile technology and to increase network security by installing the new, latest software.

You and three of your colleagues have been asked by the CEO to select an optimal software package that meets the following criteria: its practicality, utilization and cost. You must meet online to discuss the options and have a report ready by $5 \mathrm{pm}$.

Each of you is familiar with a different kind of software from your previous experience. Hence, each colleague has his/her own software option to propose. Your software to propose is OrCAD. Based on your experience at your previous company, it is easy to learn OrCAD as it perfectly handles DOS, UNIX and MAC text file formats. However, the typical difficulty you used to face was the confusion when using the datasheet graphs for filing the specs details whether to convert the Log scale into a linear scale and then insert the values or should straight away insert the numbers as per the Log scale.

\section{Your software}

OrCAD has the following technical descriptions:

- Core design tasks: Schematic and VHDL-based design entry, FPGA and CPLD design synthesis; digital, analog, and mixedsignal simulation and printed circuit board layout.

- The online demo provides all the features and functionality of the actual software, 10-3pm online helpdesk available. Purchase comes with comprehensive manual written in more than 10 languages.

- Compatible with either Microsoft or Linux operating system.

- Less time spent on the details of tool integration, devising workarounds, and manually entering data to keep files in sync.

- RM 2, 500 for 10 licenses.

\section{Your task}

You task is to meet online with your colleagues and decide together which software to recommend to your CEO. To do this, you will need to listen to, compare and contrast each other's proposal. You and your colleagues will agree on a ranking of the software. The software should be ranked from most appropriate to least appropriate for your company by filling in Sheet A.

It is your responsibility to promote your software by communicating effectively. Following the task, you will rate each other based on the criteria of effective communications found in Sheet C.

Although you will simulate a virtual meeting environment, the focus of the discussion should only be about the task mentioned. You are permitted to surf any relevant website to look for additional resources to support your arguments or to argue against your colleagues' opinions. Remember that you will need to submit Sheet A to the CEO. Note that you have to complete the task within $45 \mathrm{~min}$.

\section{Appendix B.}

\section{Examples of language activity}

The following is a dialogue between three friends who are doing a Bachelor's degree in Electrical and Electronic Engineering. Lina, Dave and Mike are discussing purchasing the software they will need to use for a course on "Electronic Circuits" next semester. Since this is a semester break, the discussion is done via text chat as everybody is in his/her hometown.

Instruction: Complete the dialogue with the appropriate auxiliary verbs.

Lina: Which software have you found (have, find) for the "Electronic Circuits" course next semester?

Dave: My suggestion would be Genius Board Circuit. Have you heard (have, hear) about it?

Mike: Yup, but it is quite expensive, isn't it?

Lina: Let's not talk about the price first. We should find software which is user-friendly.

Dave: The most important thing about GeniusBoardCircuit is that a simulated trainer is included (be, include). So, we can still continue doing our work even if our trainers are not available.Appendix C.

Comparison table (Task Structure Material)

\begin{tabular}{llll}
\hline Software & General information & Practicality & Utilization \\
\hline OrCAD & & & \\
MATLAB & & \\
Automation Studio & & \\
MAXplus II & & \\
Points & & \\
\hline
\end{tabular}




\section{Appendix D.}

\section{Recommendation worksheet}

Instruction: You should complete this and submit it to the CEO.

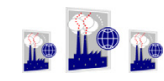

Diamond Circuit Limitedhttp://www.diamondcircuit.com.my 13 Banquet Perdana, 52200 Kuala Lumpur, MALAYSIA Phone: 0060331883188 Fax: 0060381338133 E-mail: diamondcircuit@tm.net.my

\section{INTERNAL MEMO}

\section{STRICTLY CONFIDENTIAL}

Below are the results of the virtual meeting held on Tuesday, 21st March 2006, at 14:00:00 GMT. We would like to recommend the software according to the following ranking:

\begin{tabular}{ll}
\hline No. & Software \\
\hline 1. & \\
2. & \\
3. & \\
4. & Reasons \\
\hline
\end{tabular}

Based on the above information, we recommend as the best software to be purchased by our company.

Thank You.

Prepared by:

Adam, Kuala Lumpur, MALAYSIA

Baseer, Tokyo, JAPAN

Chow, Bangkok, THAILAND

Diana, Helsinki, FINLAND

\section{References}

Adams, R., \& Nik, N. (2014). Prior knowledge and second language task production in text chat. In M. Gonzalez-Lloret, \& L. Ortega (Eds.), Technology-mediated TBLT: Researching technology and tasks (pp. 51-78). Amsterdam: John Benjamins.

Blake, C. (2009). Potential of text-based internet chats for improving oral fluency in a second language. The Modern Language Journal, 93, 227-240.

Blake, R. J. (2007). New trends in using technology in the language curriculum. Annual Review Of Applied Linguistics, $27,76-97$.

Chapelle, C. A. (1997). CALL in the year 2000: Still in search of research paradigms? Language Learning E Technology, 1, $19-43$.

Chapelle, C. A. (2004). Technology and second language learning: Expanding methods and agendas. System, 32, 593-601.

Chen, F. C., \& Wang, T. C. (2009). Social conversation and effective discussion in online group learning. Educational Technology Research And Development, 57, $587-612$.

Cheon, H. (2003). The viability of computer mediated communication in the Korean secondary EFL classroom. Asian EFL Journal 5(1) . http://asian-efljournal.com/journal-2003/.

Chun, D. M., \& Payne, J. S. (2004). What makes students click: Working memory and look-up behavior. System, 32, 481-503.

Collentine, K. (2011). Learner autonomy in a task-based 3D world and production. Language Learning E Technology, 15 (3), $50-67$.

Doughty, C., \& Long, M. (2003). Optimal psycholinguistic environments for distance foreign language learning. Language Learning E Technology, 7, 50-80.

Ellis, R., \& Yuan, F. (2004). The effects of planning on fluency, complexity, and accuracy in second language narrative writing. Studies in Second Language Acquisition, 26, 59-84.

Fiori, M. L. (2005). The development of grammatical competence through synchronous computer-mediated communication. CALICO Journal, $22,567-602$.

Foster, P., \& Skehan, P. (1996). The influence of planning and task type on second language performance. Studies in Second Language Acquisition, 18, 299-323.

Foster, P., Tonkyn, A., \& Wigglesworth, G. (2000). Measuring spoken language: A unit for all reasons. Applied Linguistics, $21,354-375$.

Gilabert, R. (2007). Effects of manipulating task complexity on self-repairs during L2 oral production. Iral-international Review Of Applied Linguistics In Language Teaching, 45, 215-240.

Housen, A., \& Kuiken, F. (2009). Complexity, accuracy, and fluency in second language acquisition. Applied Linguistics, $30,461-473$.

Jin, L., \& Erben, T. (2007). Intercultural learning via instant messenger interaction. CALICO Journal, 24, 291-311.

Johnson, G. M. (2006). Synchronous and asynchronous text-based CMC in educational contexts: A review of recent research. Tech Trends, 50, 46-53.

Kern, R. G. (1995). Restructuring classroom interaction with networked computers: Effects on quantity and characteristics of language production. The Modern Language Journal, 79, 457-476.

Kern, R. G., Ware, P., \& Warschauer, M. (2008). Network-based language teaching, 2nd ed. In N. Van Deusen-Scholl, \& N. H. Hornberger (Eds.), Encyclopedia of language and education: (Vol. 4. pp. 281-292). New York: Springer Second and foreign language education.

Kitade, K. (2008). The role of offline metalanguage talk in asynchronous computer-mediated communication. Language Learning E Technology, $12,64-84$.

Kuiken, F., \& Vedder, I. (2007). Task complexity and measures of linguistic performance in L2 writing. Iral-international Review Of Applied Linguistics In Language Teaching, 45, 261-284.

Kung, S.-C. (2004). Synchronous electronic discussions in an EFL reading class. ELT Journal, 58, 164-173.

Lai, C., \& Zhao, Y. (2006). Noticing and text-based chat. Language Learning É Technology, 10(3), 102-120.

Lee, L. (2002). Synchronous online exchanges: A study of modification devices on non-native discourse. System, 30, $275-288$.

Lee, L. (2008). Focus-on-form through collaborative scaffolding in expert-to-novice online interaction. Language Learning E Technology, 12(3), 53-72. 
Loewen, S., \& Reissner, S. (2009). A comparison of incidental focus on form in the second language classroom and chatroom. Computer Assisted Language Learning, 22, 101-114.

Long, M. H., \& Crookes, G. (1992). Three approaches to task-based syllabus design. TESOL Quarterly, 26, 27-56.

Lund, A. (2006). The multiple contexts of online language teaching. Language Teaching Research, 10, $181-204$.

Leki, I. (2009). Preface. In R. M. Manchón (Ed.), Writing in foreign language contexts: Learning, teaching, and research (xiii-xvi)Bristol: Multilingual Matters. Manchón, R. M. (Ed.), ()Writing in foreign language contexts: Learning, teaching, and research. Bristol: Multilingual Matters.

Manchón, R. M. (2012a). Situating the learning-to-write and writing-to-learn dimensions of L2 writing. In R. M. Manchón (Ed.), Learning-to-write and writing-to-learn in an additional language (pp. 1-14). Amsterdam: John Benjamins.

Manchón, R. M. (2012b). Writing to learn the language: Issues in theory and research. In R. M. Manchón (Ed.), Learning-to-write and writing-to-learn in an additional language (pp. 61-82). Amsterdam: John Benjamins.

Meskill, C. (2005). Triadic scaffolds: Tools for teaching English language learners with computers. Language Learning E’ Technology, 9(1), 46-59.

Michel, M. C., Kuiken, F., \& Vedder, I. (2007). The influence of complexity in monologic versus dialogic tasks in Dutch L2. Iral-international Review Of Applied Linguistics In Language Teaching, 45, 241-259.

Nation, I. S. P. ([240_TD\$DIFF][210_TD\$DIFF]2004). A study of the most frequent word families in the british national corpus. In P. Bogaards, \& B. Laufer (Eds.), Vocabulary in a second language: Selection, acquisition, and testing (pp. 3-13). Amsterdam: John Benjamins.

Nik, N., \& Adams, R. (2009). TBLT and SCMC: How do students use communication strategies? Asian Journal Of English Language Teaching, 19, 135-158.

Nik, N., Adams, R., \& Newton, J. (2012). Writing to learn via text chat: Task implementation and focus on form. Journal Of Second Language Writing, 21, 23-39.

Norris, J. M., \& Ortega, L. (2009). Towards an organic approach to investigating CAF in instructed SLA: The case of complexity. Applied Linguistics, $30,555-578$.

Nuevo, A. M. (2006). Task complexity and interaction: L2 learning opportunities and development. Georgetown University (Unpublished doctoral dissertation).

Nuevo, A. M., Adams, R., \& Ross-Feldman, L. (2011). Task complexity, modified output, and 12 development in learner-learner interactions. In P. Robinson (Ed.), Second language task complexity: Researching the cognition hypothesis of language learning and performance (pp. 175-202). Amsterdam: John Benjamins.

Ong, J., \& Zhang, L. J. (2010). Effects of task complexity on the fluency and lexical complexity in EFL students' argumentative writing. Journal of Second Language Writing, 19, 218-233.

Ortega, L. (2009). Interaction and attention to form in 12 text-based computer-mediated communication. In A. Mackey, \& C. Polio (Eds.), Multiple perspectives on interaction in second language acquisition: Second language research in honour of Susan M. Gass (pp. 226-253). New York: Taylor \& Francis.

Ortega, L. (2012). Epilogue: Exploring L2 writing-SLA interfaces. Journal Of Second Language Writing, 21, 404-415.

Pallotti, G. (2009). CAF: Defining, refining and differentiating constructs. Applied Linguistics, 30, 590-601.

Peterson, M. (2010). Task-based language teaching in network-based call: an analysis of research on learner interaction in synchronous cmc. In M. Thomas, \& H. Reinders (Eds.), Task-based language learning and teaching with technology (pp. 41-62). London: Continuum.

Philp, J., Adams, R., \& Iwashita, N. (2014). Peer interaction and second language learning. New York: Routledge.

Rethinasamy, S., \& Chuah, K. M. (2011). The Malaysian University English Test (MUET) and its use for placement purposes: A predictive validity study. Electronic Journal of Foreign Language Teaching, 8, 234-245.

Révész, A. (2009). Task complexity, focus on form, and second language development. Studies In Second Language Acquisition, 31, 437-470.

Robinson, P. (2001). Task complexity, cognitive resources, and syllabus design: a triadic framework for examining task influences on sla. In P. Robinson (Ed.), Cognition and second language instruction (pp. 287-318). Cambridge: Cambridge University Press.

Robinson, P. (2005). Cognitive complexity and task sequencing: Studies in a Componential Framework for second language task design. Iral-international Review Of Applied Linguistics In Language Teaching, 43, 1-32.

Robinson, P. (2007). Task complexity, theory of mind, and intentional reasoning: Effects on L2 speech production, interaction, uptake and perceptions of task difficulty. IRAL-International Review of Applied Linguistics in Language Teaching, 45, 193-213.

Robinson, P., \& Gilabert, R. (2007). Task complexity, the Cognition Hypothesis and second language learning and performance. Iral-international Review Of Applied Linguistics In Language Teaching, 45, 161-176.

Sanders, R. (2006). A comparison of chat room productivity: In-class versus out-of-class. CALICO Journal, $24,59-76$.

Sauro, S. (2009). Computer-mediated corrective feedback and the development of L2 grammar. Language Learning E Technology, 13, 96-120.

Sauro, S. (2011). SCMC for SLA: A research synthesis. CALICO Journal, 28, 369-391.

Sauro, S., \& Smith, B. (2010). Investigating L2 performance in text chat. Applied Linguistics, 31, 554-577.

Skehan, P. (1998). A cognitive approach to language learning. Oxford: Oxford University Press.

Skehan, P., \& Foster, P. (1997). Task type and task processing conditions as influences on foreign language performance. Language Teaching Research, 1, 185211.

Smith, B. (2003). The use of communication strategies in computer-mediated communication. System, 31, 29-53.

Smith, B. (2004). Computer-mediated negotiated interaction and lexical acquisition. Studies In Second Language Acquisition, $26,365-398$.

Smith, B. (2008). Methodological hurdles in captures CMC data: The case of the missing self-repair. Language Learning E Technology, $12,85-103$.

Smith, B. (2009). The relationship between scrolling, negotiation, and self-initiated self-repair in an SCMC environment. CALICO Journal, $26,231-245$.

Sotillo, M. S. (2005). Corrective feedback via instant messenger learning activities in NS-NNS and NNS-NNS dyads. CALICO Journal, $22,467-496$.

Stockwell, G. (2010). Effects of multimodality in computer-mediated communication tasks. In M. Thomas, \& H. Reinders (Eds.), Task-based language learning and teaching with technology (pp. 83-104). London: Continuum.

Swain, M. (2000). The output hypothesis and beyond: mediating acquisition through collaborative dialogue. In J. Lantolf(Ed.), Sociocultural theory and second language learning (pp. 97-114). Oxford: Oxford University Press.

Tavakoli, P., \& Foster, P. (2008). Task design and second language performance: The effect of narrative type on learner output. Language Learning, 58, 439-473.

Tavakoli, P., \& Skehan, P. (2005). Strategic planning, task structure, and performance testing. In R. Ellis (Ed.), Planning and task performance in a second language (pp. 239-273). Amsterdam: John Benjamins.

Traphagan, T. W., Chiang, Y.-H. V., Wattanawaha, B., Lee, H., Mayrath, M. C., Woo, J., Yoon, H.-J., Jee, M. J., \& Resta, P. E. (2010). Cognitive, social and teaching presence in a virtual world and a text chat. Computers \& Education, 55, 923-936.

Thomas, M., \& Reinders, H. (2010). Task-based language learning and teaching with technology. London: Continuum.

Van Deusen-Scholl, N., Frei, C., \& Dixon, E. (2005). Co-constructing learning: The dynamic nature of foreign language pedagogy in a CMC environment. CALICO Journal, 22, 657-678.

Vermeer, A. (2000). Coming to grips with lexical richness in spontaneous speech data. Language Testing, 17, 65-83.

Warschauer, M. (1995). Comparing face-to-face and electronic discussion in the second language classroom. CALICO Journal, 13, 7-26.

Wigglesworth, G., \& Storch, N. (2012). What role for collaboration in writing and writing feedback. Journal Of Second Language Writing, 21, 364-374.

Williams, J. (2012). The potential role(s) of writing in second language development. Journal Of Second Language Writing, 21, 321-331.

Yilmaz, Y. (2011). Task effects on focus on form in synchronous computer-mediated communication. The Modern Language Journal, 95, 115-132.

Yuan, F., \& Ellis, R. (2003). The effects of pre-task planning and on-line planning on fluency, complexity and accuracy in L2 monologic oral production. Applied Linguistics, 24, 1-27.

Rebecca Adams is the Associate Director of the Faculty Resource Center at Northcentral University. Her research focuses on task-based language teaching, particularly on task-based interactions among language learners. Her 2013 co-authored book Peer Interactions in Second Language Learning was published by Taylor and Francis. 
Nik Aloesnita bt Nik Mohd Alwi is a senior lecturer at Universiti Malaysia Pahang, Malaysia. Her research interests are in the area of second language acquisition, task-based language learning and technology-enhanced language learning.

Jonathan Newton is a senior lecturer at Victoria University of Wellington, New Zealand. His research interests include L2 vocabulary acquisition, learning through tasks, and intercultural language teaching and learning. He has co-authored two books: Teaching ESL/EFL Listening and Speaking (2009) and Workplace talk in action: An ESOL resource (2010). 